\title{
Conscious Intra-Personal Development: The Experience Counts
}

\author{
Dr. Rosalie van Baest
}

\begin{abstract}
The future of mankind will depend on the ability of the individual to acquire Self-knowledge. The preservation of autonomy of the individual is supported by learning to fathom one's own unconscious and inner being, the undiscovered self. By consciously developing Self-knowledge the possibility originates for the individual to make his own conscious choices and to understand an other human being. It often takes a great deal of effort from an individual to consciously open up to his inner being. Gaining experiences related to intra-personal development and consciously reflecting on those experiences, is essential to keep the conscious intra-personal development process in motion. Education can lend a helping hand during this process, from the start of the school career of children, by making room in the curriculum for affective and experiential education. Theory disturbs the experiential orientation and the focus on emotions. Offer affective and experiential education to children from an early age, with plenty of personal room, and continuing this form of education until they leave school, supports young people to become more and more self-directing. The way in which this form of education is taken care for is crucial for its success.
\end{abstract}

Keywords: Conscious Intra-personal Development - The Unconscious - Autonomy Affective and Experiential Education - Process

\section{Introduction}

In this article the importance of conscious intra-personal development for the individual emerges. The process of conscious intra-personal development is placed in an educational context. The connection between 'Why searching the way to the inner self?' and 'How to stimulate conscious intra-personal development in education?'will come to the fore.

Carl G. Jung (C. G. Jung 1865-1961) wrote the book 'The Undiscovered Self' in 1957. In the book Jung gives his view, from his experiences as a psychiatrist, on the importance of searching the way to the inner Self. He stresses the significance of conscious intra-personal development by the individual for the future of mankind 
(and of the earth and everything that lives on it. Remark of the author). The ability of the individual to acquire Self-knowledge, the preservation of autonomy of the individual, lead possibly to conscious personal choices. Only by sensing and understanding his own unconscious, the undiscovered Self, the individual can get through to his inner Self. This requires of the individual to face his fear for his own unconscious.

The view of Carl G.Jung on searching the way for the inner Self, in his book "The Undiscovered Self", is the basis for the article.

It is often very difficult for an individual to make a start with the search for the inner path, let alone to shape it. Therefore, some support at the start of the conscious intrapersonal development process is valuable. Education is there for (almost) everyone and for that reason education has the opportunity to offer support to (almost) everyone in gaining experience with the conscious intra-personal development process, from the start of the school career of young people until they leave school. A way to start the support of this process for young people in education is affective, experiential and student-oriented education. The attitude and role of the experiential teacher is of great importance in affective and experiential teaching. (Van Baest 2017).

\section{Contents}

Part 1 of the article focuses on the view of Carl G. Jung, about searching a way to the inner Self, in his book 'The Undiscovered Self'. His view is related to conscious intrapersonal development.

Part 2 is focused on how to stimulate conscious personal development in education.

Part 3 goes into themes that play a role in the process of conscious intra-personal developmemt (in education).

Part 4 focuses on some points of interest for the approach of affective and experiential education.

\section{Why searching the way to the inner self?}

'Until you make the unconscious conscious, it will direct your live and you will call it fate'. 
In this part of the article, the view of Carl G. Jung in his book 'The Undiscovered Self', comes to the fore; this view is related to the conscious development of Selfknowledge.

Jung creates an image of the world we live in and the role of humanity in it. In the book, he expresses his great concern about the future of humanity and (remark of the author) therefore also about the future of the earth and everything that lives on it.

On what does an individual base his choices? On external factors: on what happens in his environment, on what is possible at a certain moment, on what everyone is doing? Or on his personal values, on his Self-knowledge, on his possibilities and qualities? An individual who consciously develops his Self-knowledge will not only be guided by external circumstances, but also by his inner being. Too much attention for the environment, creates blockades for direct inner experiences.

There is another blockade for achieving Self-knowledge: fear of what the individual might encounter in the unconscious part of his psyche. In fact the individual thus ignores a part of his Self. Fear of the unconscious stands in the way of the development of Self-knowledge.

When an individual opens up to his unconscious, searching for his Self, estrangement from his environment is an inevitable and logical consequence. The path to the inner Self is a personal path, a path the individual can only follow himself. The search for this inner path irrevocably involves estrangement from one's surroundings.

In spite of these obstacles, the conscious intra-personal development of the individual is a necessary solution to the major problems, facing and to be faced by humanity. The conscious part of an individual's psyche that opens up to his unconscious, learns to listen to it and thus increasingly can come closer to his Self, his whole inner being.

\section{Gap between knowledge and feeling}

For many years the gap between knowledge and feeling has deepened, between knowing and understanding, between the conscious and unconscious aspects of the human psyche.

Intra-personal development and the development of personal values and norms lag behind the rapid developments in science, technology and society. The balance between emotions and knowledge is lost. Knowledge alone is not enough to solve the major problems of humanity or to give them a push in the right direction.

If the individual is satisfied with his circumstances, he will accept his situation. The individual is often so busy with what is happening around him, he does not take time to focus on his inner being. However, when circumstances change, and there has been no learning process to achieve autonomous functioning, the individual will easily focus on what everyone is doing. In this situation, it is not inconceivable that the individual considers external circumstances to be responsible for the choices he 
makes. However, external circumstances cannot take responsibility for the choices the individual has made. External circumstances have no choice, no norms and values. Individuals do or could have them.

'The forlornness of consciousness in our world is due primarily to the loss of instinct, and the reason for this lies in the development of the human mind over the past aeon. The more power men had over nature the more his knowledge and skill went to his head'. (Jung 1957).

The unconscious is everything that the conscious is not. It manifests itself through opposite feelings, fantasies, emotions, impulses and dreams, which come up unasked for by the individual. What feelings and impulses does an individual experience in the activities he undertakes? Does he consciously reflect on what is going on in his unconscious or does the conscious part of the individual's psyche shut itself off from the unconscious? The conscious will have to take into account the existence of unconscious factors that require attention. If the conscious part of the psyche wants to be open to the unconscious factors, the conscious will first have to get to know the essence of these unconscious factors, he will have to experience them. A consequence of shutting oneself off from the unconscious is that the individual only knows himself partly.

'Accordingly we imagine ourselves to be innocuous, reasonable and humane. We do not think of distrusting our motives or of asking ourselves how the inner man feels about the things we do in the outside world. But actually it is not good and psychically right, to overlook the reaction and standpoint of the unconscious. One can regard one's stomach or heart as unimportant and worthy of contempt, but it does not prevent overeating or overexertion from having consequences that affect the whole man. Yet we think that psychic mistakes and their consequences can be got rid of with mere words'. (Jung 1957).

The process of conscious intra-personal development is not a theoretical learning path. The search for the inner path is guided by individual experiences, of which emotions are an essential part.

\section{Knowledge or understanding}

When an individual consciously develops his Self-knowledge, will he be supported by knowledge and theories? In his book 'The Undiscovered Self' Jung expressly indicates the difference between knowledge and understanding in the context of conscious intra-personal development. When it comes to developing Self-knowledge or understanding an other human being, knowledge and theory should be omitted. Knowledge and understanding follow a different path each and can not be intertwined; it should be clear which of the two paths is being followed. 
Theory is not related to individual experiences, to isolated facts, but to abstractions and generalities. Self-knowledge is an individual matter; only the individual can sense and follow

his intra-personal development. Conscious development of Self-knowledge is not based on theoretical assumptions. You walk the path inwards on your own and you have little use for knowledge and theory if you want to understand a fellow human being.

\section{Self-knowledge}

The conscious part of the psyche admits the unconscious part, thinks about the unconscious part and gives it a place. In the unconscious resides opposite feelings, impulses and dreams. What do these feelings, dreams, impulses mean to me and how can I deal with them? The conscious part of the psyche admits the unconscious part, to become a complete human being. Jung indicates that a profound change in the inner Being of man, will become more and more important in the future. (1).

Note ' Anyone who has ego-consciousness at all takes it for granted that he knows himself, but the ego knows only its own contents, not the unconscious and its contents. People measure their self -knowledge by what the average person in their social environment knows of himself, but not by the real psychic facts which are for the most part hidden from them. What is commonly called self- knowledge is therefore a very limited knowledge, most of it dependent on social factors, of what goes on in the human psyche'. (Jung 1957).

Only the individual can seek his inner Being within himself by looking openly and honestly at his feelings, his dreams, his good and bad sides, his prejudices and assumptions about himself and the other. More and more facing his thoughts and feelings, to realise where he stands and what path he would like and could take in his life. To see himself as he is and therefore to be able to see his fellow man in a different perspective, because as an individual he has started to think and feel differently.

If an individual has turned inwards and gained insight into his Self and his actions, he has found access to the unconscious and, without realising it, has created a possibility to influence his surroundings.

\section{The individual and the intra-personal path}

\section{The individual}

The only one who can follow his inner path is the individual, who is open for his intrapersonal development process, for his unconscious. To start with the conscious development of the inner path requires great effort. 
'It usually costs people an enormous effort to help the first stirrings of individuality into consciousness, let alone put them into effect'. (Jung 1957).

In the end, focusing on the inner Self, will provide the individual with more insight into his total humanity.

\section{The individual and his social environment}

No one can walk on the intra-personal path for another individual.

The environment or society are not capable of giving the individual intra-personal development. Every individual will have to acquire this himself, at the cost of a great deal of effort.

By learning to understand his inner Self, the possibility arises to come to a mutual understanding of one's fellow man.

\section{The individual and society}

The value of a society consists of the spiritual and moral content of the individuals comprising it.

\section{How to stimulate conscious intra-personal development in education?}

Stimulating the conscious intra-personal development process, stimulating the conscious search for the inner path. was and is not self-evident in education. Affective and experiential education can support this process.

Conscious personal development may lead to conscious choices. Not only on a personal level, but also on a professional level'. (Van Baest 2017).

The inner path is an individual path and is different for each individual. Experience that supports the conscious intra-personal development is gained by feeling something yourself, by observing and being involved in certain processes. Affective and experiential education is about gaining experience with personal qualities, to reflect on the experience and to learn from it.

The way in which the search of the individual for his inner path will go, is of great importance for the direction of his path.

\section{Affective and experiential education}

The focus in affective and experiential education is on personal qualities, as: selfesteem, ambition, stress-resistance, motivating and stimulating ability, integrity, responsibility, creativity (Gramsbergen-Hoogland 1999). The aim of the experiential and affective education is to introduce unexpected and surprising experiences related to personal qualities that enables a person to consciously experience his thoughts, feelings and ideas about his personal qualities and to reflect on them. 
The following is an example of an affective and experiential assignment: the 'Learning style test of Kolb'.

Learning about your personal learning style offers a perspective on the way you learn. During an affective and experiential meeting, the learning style test of Kolb is worked out and discussed, together with all students (in this case the test was in Higher education) present in the classroom. The test is easy to fill in and it does not take a lot of time. The aim is to provide a beginning insight into the personal learning style, but also to obtain information about the learning styles of group members. First of all the students fill in the test, without too much explanation.

When they finish the test the students receive a text with a description of the learning styles. There are four learning styles: the dreamer, the thinker, the decision-maker and the doer. It is important that each student endorses the outcome of his learning style test. Only the student himself can sense in which learning style he recognizes himself and in which learning style he might develop himself. Possibly the student always encounters the same problem during group work, caused by a learning style he has not (yet) developed (or not sufficiently). Each student indicates in the group which learning style has emerged from the test and whether he agrees with this result.

For the lecturer, it is essential that substantiated feedback can be given to the students about their learning style. (Van Baest 2016-2017-2019).

'When it is used in the simple, straightforward, and open way intended, The LSI usually provides valuable self-examination and discussion that recognizes the uniqueness, complexity, and variability in individual approaches to learning. The danger lies in the reification of learning styles into fixed traits, such that learning styles become stereotypes used to pigeonhole individuals and their behaviour' (Kolb 1981-2005).

Constantly gaining new experiences related to personal qualities during experiential and affective education and reflect consciously on them, offers the possibility to deepen the insight into one's own personal qualities; the learning process of conscious intra-personal development.

Gaining experience with a way to approach the conscious intra-personal learning process, provides a basis for recognising and developing the personal learning process, thus creating more and more opportunities for self-directing. Self-directed learning is essential for learning to learn and lifelong learning. Openness to the intrapersonal learning process remains important throughout life.

Information about personal development, from the lecturer to the students, without the students gaining experience themselves, provides information about personal development but no personal experience to support the inner path. 


\section{The experiential lecturer}

The affective and experiential teacher has an essential role. A flexible attitude is a basic characteristic of the experiential teacher. The teacher's attitude and communicative style are part of affective and experiential education.

The lecturer's learning process, as part of the affective and experiential meetings, takes several years: the experiential lecturer has consciouly gained experience with all kind of aspects of his personal qualities and reflected on them. The possibility to offer experiential, affective and student-oriented education requires time and space on the part of the lecturer.

The experiential teacher has a complex role when it comes to education in which conscious development of self-knowledge is the essence.

Where lies the lecturer's interest, in knowing or understanding? Is the lecturer pupiloriented or more knowledge-oriented? Has the lecturer gone through the process of conscious intra-personal development himself? Does stimulating conscious intrapersonal development fit his personality? Is the lecturer supportive of affective and experiential education? Can he shield the meetings from knowledge and theory? Does he himself want to engage in lifelong learning? Does the lecturer have a flexible attitude?

Starting up and building up a digital network for teachers involved in affective and experiential education, an E.T.W.W. (Experiential Teacher Wide Web), can provide support in the development of this form of education. Teachers from all kind of educational situations might exchange ideas, ask each other questions, answer each other's questions and provide each other with constructive feedback. An experiential assignment from group 2 of the primary school can also give a teacher from secondary or higher education ideas and vice versa. A digital network for experiential teachers, an E.T.W.W., can deepen and broaden the way in which affective and experiential education works.

\section{Affective and experiential education for young children}

An example of an interpretation of affective and experiential education can be seen in the documentary 'Just a Beginning', ('Ce n'est qu'un début' 2010), which was recorded in group 1 and 2 of a primary school in a village near Paris. In this documentary, children are offered affective and experiential education at a very young age: the 'philosophy lesson', the reflection lesson or PHILO, as the children call the lesson. By sharing experiences in the classroom that focus on conscious intra-personal development, on the emotions, thoughts and ideas of each pupil in the group, it supports opening up to the intra-personal path and at the same time provides insight into the emotions, thoughts and ideas of the classmates, interpersonal development. 
The teacher of group 1 and 2 stimulates the children to think and talk together about personal experiences, behaviour and emotions concerning themes such as: love, friendship, death, mum and dad. After all, on the outside nobody can see what your thoughts are. The teacher asks a question and leaves the communication as much as possible with the pupils and tries to steer the conversation as little as possible. The lessons start every time when the children and the teacher sit in a circle and the teacher lights a candle, a symbol for the beginning of the philosophy lesson. The candle is placed in the middle of the circle. At the beginning of the documentary, the children talk more and listen to each other less; private conversations take place. But things are getting better and better. The children learn to express their thoughts, to express their emotions consciously and to listen to each other. Some children are very sad that the philosophy lessons stops when they go to group 3 the next school year. Some children don't mind. A little boy indicates that he doesn't like all that thinking and talking, but he has thought about it and can express his thoughts well.

'The stimulation of new educational concepts better suited to our multidisciplinary society demands a dynamic setting that is difficult to predefine in literature. Which educational methodology is most appropriate for stimulating the desired learning process? How do people learn self-management? How do you facilitate reflection? Which learning processes ensure that people become more motivated? These learning processes involve behavioural change, personal development and emotions. Changing concepts and visions require more than just the ability to reproduce existing knowledge. These types of change processes are far more complex than traditional knowledge transfer' (Shulman 2006).

\section{Themes of the process of conscious intra-personal development in education}

Wisdom is the child of experience. Leonardo da Vinci.

A number of themes are essential points of attention during the process of conscious intra-personal development, throughout all school years. All themes have a share in affective and experiential education.

\section{Self-knowledge through experience}

Gaining experience related to the conscious search for the inner path, is essential in the process of conscious personal development. Without experiences related to conscious intra-personal development, the inner path is difficult passable. The inner path is an individual path and is different for each individual. Experience is gained by discovering, feeling and observing something yourself, what can be completely clear to one individual, can be completely invisible to another. Being aware of one's own paradigm (Barker 1996), personal qualities, strenghts and weaknesses, offers the opportunity to work on desired adaptations.

It is often very difficult for an individual to make a start with the inner path, let alone to shape it. Therefore, some support at the start of the conscious intra-personal 
development process is valuable. Education is there for (almost) everyone and for that reason education has the opportunity to offer support to (almost) everyone in gaining experience with the conscious intra-personal development process.

\section{Interpersonal development}

Every human being has his own paradigm, his own point of view (Barker 1996). A shared experience in a group during education makes it possible to discuss together the experience, the emotions felt and the reactions to it. It makes clear that not everyone has felt and experienced the same, so that everyone's perspective can broaden and deepen. Understanding a different perspective becomes possible. When each group member discusses his reflection on an experience, it gives a picture of the personal view of each group member to the other group members.

\section{Conscious reflecting}

Learning to reflect consciously on personal qualities (Denton 2011) and to express thoughts, feelings and ideas about them, by gaining experience during experiential meetings in education, is valuable. A number of questions can arise during the conscious reflection on the meeting, such as: what does this experience mean for me, which emotions play a role, can I explain my reactions, how did I deal with these emotions and my reaction to them? In what way did the group members react on my behaviour during the experience, which emotions evoked in me and how did I deal with them? Learning to reflect requires a conscious learning process. Writing down the reflections on the experiential meetings in a reflection notebook, supports the conscious intra-personal learning process (Bolin 2005). It's about understanding the conversation within your Self. An inner exchange of ideas. In this conversation conscious decisions can be made, for example: 'don't react immediately, first take a step back and think about the situation'.

The young children in the documentary 'Just a Beginning' do not yet consciously note down thoughts, feelings and opinions. But the children develop a certain sensitivity for reflecting, expressing thoughts and feelings, and listening to each other.

\section{Openness}

If an individual is not open to conscious intra-personal development, it is difficult to find and follow the inner path. Being open to the inner path is the starting point. The attitude of a person makes it clear whether or not he is motivated to work out the experiential assignments. The children from the documentary 'Just a Beginning' clearly show who is open to the 'philosophy lesson' at a certain moment.

\section{Internalising}

Repetition plays a major role in internalising intra-personal development. For example, gaining experience with the working out of the learning style test of Kolb several times, contributes to the internalisation of the personal learning style and the 
comprehension of its consequences: what is going well in my way of learning and on what do I still have to work?

\section{Autonomy}

Autonomy is the ability of the individual to choose a goal by himself, to make decisions that enable the achievement of the goal set, and then to achieve the goal set by himself. (Vergeer, 2001). Autonomy means "providing yourself with laws". (Swaine, 2012). Learning to make reasoned choices and to make well-grounded decisions, in order to become more self-directing and to hold as good as possible.

Autonomous functioning and making one's own choices is a prerequisite for the conscious development of Self-knowledge. In an educational environment in which autonomous action is not supported, it is difficult to develop personal qualities and act from intrinsic motivation.

In order to practise individual autonomy, to develop self-directing, space is needed for a learning process in which the practice and shaping of personal values (moral identity) through play, creativity and the growth of affective and cognitive capacities has a place'. (Strain quoted in Zhao, \& Biesta, 2012) in Van Baest, 2017).

When a choice has to be made, it makes sense to assess and oversee the possibilities and consequences of the choice as well as possible in advance. Not to be guided by impulses or what everyone would do, but to think about: who am I, what can I do, what do I want and what do I choose?

How can an individual protect himself against the pressures of an ever more rapidly changing world, in which he has to make choices over and over again, and maintain his autonomy? Making choices based on what happens around him, what everyone does, often seems to be the only way to go in the short-term.

In addition to a personal meaning, autonomy also has a social meaning, aimed at interpersonal relationships: an interpersonal behaviour that one person adopts in relation to another. (Reeve \& Jang, quoted in Leroy, et al. 2007). In other words: will and can one person support the autonomy of the other person, while at the same time he maintains his own autonomy.

\section{'If mankind does not turn inwards, the future doesn't} look good'.

(Shambhala Tibet)

\section{Morals, ethics, values and norms}

If you are not aware of your own values and norms, if you are not aware they guide your actions, making (ethical) choices, especially in a situation where you are faced with an ethical dilemma, remains a matter for 'the other'. Every path you take is a good one. You don't have to make your own choices, so you don't have to take 
responsibility for the consequences? If you use moral excuses ('I can't do anything about that, everyone does it') then you put the responsibility somewhere else. Showing moral courage is not self-evident. It's easier to do what you're told to do or do what everyone else does and not think about it too much. Jung asks himself in his book 'The Undiscovered Self' whether it would not have been possible to make other choices than developing weapons of destruction, a choice that would have benefited mankind and the earth?

One of the forms of evil is academic evil (Stangneth 2017), in which thinking is disconnected from moral choices, from emotions. The world is only understood in the light of a dominant system of thought, whether it is 'capital, making money', 'selfinterest', 'technology', 'authority, hierarchy, doing what the boss says' or 'an ideology', which means that you no longer appear to yourself as an acting person. (Stangneth 2017).

Opening up to one's own values and norms and reflecting on them consciously, offers the opportunity to make conscious personal choices. Providing opportunities for young people to gain experience with their values and norms during education, is important to stimulate awareness and to develop a certain sensitivity to ethical issues. Knowing what emotions play a role in all kind of experiences related to the personal values and norms, offers the possibility to make conscious personal choices, to take and bear one's own responsibility.

We all walk in the dark. Everyone has to turn on their own light'. Catherine Heburn.

\section{Conscious intra-personal development: a lifelong learning process}

Finding one's way to the inner self is a lifelong development process in which an individual can always come up against surprises. The conscious intra-personal development process is driven by experiences gained, to recognize the emotions and thoughts evoked in this process, to think about them and to do something with them. During life an individual is confronted with many things and circumstances: with his own possibilities and qualities, with his personal circumstances, his choices and the consequences thereof, with illness, death, events affecting people in his social environment, with circumstances in the world, the situation at work. Slowly a selfimage emerges, (who am I, what can I do, what do I want and what do I choose?), which in the course of life has to be constantly adjusted by gaining other insights. Flexibility plays an important role in the learning process. Insight in yourself does not arise at once, changes within the inner self do not take place in the short term. It is a lifelong process.

In order to be able to find a way in all kind of circumstances, it is essential that an individual gets to know himself in order to be able to determine his course from that 
point on. During the conscious intra-personal development process, the conscious admits the unconscious, reason interacts with emotion.

The intra-personal path is not an easy one. It takes time and effort to get on and stay on the road. That is why some support during the development of the intra-personal learning process in education would be valuable.

\section{Points of interest for the approach of affective and experiential education}

This article ends with some points of special interest for the approach of affective and experiential meetings in education.

- Affective and experiential meetings are organised several times per educational situation in every school year, from primary education to secondary and higher education, if possible with the same group members each year. This provides a common thread in the conscious intra-personal development process. Gaining joint experiences offer more insight into oneself and provides insight into the reactions of the other group members. Young people learn from the personal reactions of their classmates or group members to the same experiences during the meetings; there are also other ways to react to situations than their own. Developing more of a group feeling requires taking other views into account. Being open to someone else, opens the way for less projection and a deeper understanding.

- Joint affective and experiential meetings offer a handle on one's own intra-personal development process. The growth of self-confidence is given room. It is valuable when young people, as part of their intra-personal development, become aware of themselves and learn to express their thoughts, emotions and ideas. Perhaps they develop a helicopter view to look at themselves and others. When children get in touch with conscious intra-personal development at an early age, they have more time and space to experience the intra-personal learning process during education. Gaining experience, reflecting and expressing thoughts, feelings and opinions in a group, as for example in the documentary 'Just a Beginning', (Ce n'est qu'un début) is valuable for young people to start the conscious intra-personal search. Each pupil follows his or her own path until they leave education. When they leave school, they have the possibility to consciously direct their own learning and make conscious personal choices. Individuation is a learning process: the path to the unification of the Self by gaining insight into one's own psyche, into the conscious and the unconscious, into one's own human being.

- A flexible approach of the lecturer is essential; every educational situation requires a different approach and variation. Starting up and developing an E.T.W.W. (Experiential Teacher Wide Web) can offer the experiential teacher support in providing experiential education. Teachers from all kinds of educational situations exchange ideas. This can deepen and broaden the way in which affective and experiential education works. A feeling of support for the experiential teacher. 
Offering theory during the meetings disturbs the experiential orientation and the focus on emotions. At the start of the school career, the meetings are intended to get used to the approach of affective and experiential education and to get acquainted with a number of personal skills. With a new group, the experiential teacher also makes a new start in stimulating the conscious intra-personal learning process of the group members: giving room to each group member to gain experience in his or her own way in the new group.

- An important factor for the success of this form of education is the way in which the affective and experiential meetings go. If pupils can attend affective and experiential meetings in education from an early age and it is a positive, continuous path for them until they leave education, then they know how to reflect, to listen and observe and they have experienced the value of personal qualities for themselves.

'Subjective well-being refers to what people think and how they feel about their lives, to the cognitive and affective conclusions they reach when they evaluate their existence'. (Seligman, \& Csikszentmihalyi, 2000).

It has become possible to discuss their emotions, thoughts, and ideas on all kinds of personal themes. What influence did the development of their inner Being have on their choices? They gained insight into the personal development process they have gone through and what it has meant for them.

\section{References}

[1] Barker J (1996) Paradigms. Mental models for the future. (Paradigms. Mental models for the future). Scriptum Books.

[2] Bolin AU, Khramtsova I, Saarnio D (2005) Using Student Journals to Stimulate Authentic Learning: Balancing Bloom`s Cognitive and Affective Domains. Teaching of Psychology 32 (3), 154159).

[3] Da Vinci L (2007) The Thoughts of Leonardo da Vinci (Éditions du Clos Lucé. Translation: Lidewij van den Berg for LinduaNet-France)

[4] Denton D (2011) Reflection and Learning: Characteristics, obstacles, and implications. Educational Philosophy and Theory 43 (8), 838-852.

[5] Gramsbergen-Hoogland YH, Deveer MAJ, Leezenberg MG (1999) Personal quality. Publishing house Wolters Noordhoff.

[6] Jung CG (1957) The Undiscovered Self. Published by New American Library

[7] Kolb A, Kolb D (2005) The Kolb Learning Style Inventory-Version 3.1. 2005 Technical Specifications. HayGroup. LSI Technical Manual.

[8] Leroy N, Bressoux P, Sarrazin P, \& Trouilloud D (2007) Impact of teachers 'impliciet theories and perceived pressures on the establishmentof an autonomy supportive climate. European Journal of Psychology of Education

[9] Pozzi J-P, Barougier P (2010) Just a Beginning (Cést seulement un début) Wild Bunch Benelux Distribution 
[10] Seligman M, Csikszentmihalyi M (2000) Positive Psychology, An Introduction. American Psychologist 55(1): 5-14.

[11] Shulman LS in: Lectoraat Pedagogiek van de Beroepsvorming van de Haagse Hogeschool/TH Rijswijk (2006). Koninklijke De Swart, The Hague 1-244.

[12] Stangneth B (2017) Het Kwade Denken Uitgeverij Atlas Contact

[13] Swaine L (2012) The false right to autonomy in education. Educational Theory 62 (1), 107-124.

[14] Van Baest R (2017). Conscious Development Stimulating Movement Mechanism in Technology Education. Doctoral research (Ph D), Faculty of Human Studies, Tilburg University.

[15] Van Baest R (2016) SCS (Social and Communication Skills). International Symposium on Project Approaches in Engineering Education, PAEE/ALE 2016 Volume 6, 100-109.

[16] Van Baest R (2019). Stimulating Conscious Development Mechanism for Movement in Education. Athens Journal of Technology \& Education. 6 (3) doi=10.30958/ajte.6-3-4

[17] Vergeer F (2001) Autonomy and well-being. (Autonomy and well-being). Thesis (Ph D) at the Catholic University of Nijmegen.

[18] Zhao K, Biesta G (2012) The Moral Dimension of Lifelong Learning: Giddens, Taylor, and the "Reflexive Project of the Self". Adult Education Quarterly 62 (4), 332-350. 